\title{
Better constraints on the sea-ice state using global sea-ice data assimilation
}

\author{
P. Mathiot ${ }^{1,2}$, C. König Beatty ${ }^{1}$, T. Fichefet ${ }^{1}$, H. Goosse ${ }^{1}$, F. Massonnet ${ }^{1}$, and M. Vancoppenolle ${ }^{1,3}$ \\ ${ }^{1}$ Georges Lemaître Centre for Earth and Climate Research, Earth and Life Institute, Université Catholique de Louvain, \\ Belgium \\ ${ }^{2}$ British Antarctic Survey, Natural Environment Research Council, Cambridge, UK \\ ${ }^{3}$ Laboratoire d'Océanographie et du Climat, Institut Pierre-Simon Laplace, Paris, France
}

Correspondence to: P. Mathiot (pierre.mathiot@bas.ac.uk)

Received: 14 May 2012 - Published in Geosci. Model Dev. Discuss.: 19 June 2012

Revised: 1 October 2012 - Accepted: 5 November 2012 - Published: 3 December 2012

\begin{abstract}
Short-term and decadal sea-ice prediction systems need a realistic initial state, generally obtained using iceocean model simulations with data assimilation. However, only sea-ice concentration and velocity data are currently assimilated. In this work, an ensemble Kalman filter system is used to assimilate observed ice concentration and freeboard (i.e. thickness of emerged) data into a global coupled oceansea-ice model. The impact and effectiveness of our data assimilation system is assessed in two steps: firstly, through the use of synthetic data (i.e. model-generated data), and secondly, through the assimilation of real satellite data. While ice concentrations are available daily, freeboard data used in this study are only available during six one-month periods spread over 2005-2007. Our results show that the simulated Arctic and Antarctic sea-ice extents are improved by the assimilation of synthetic ice concentration data. Assimilation of synthetic ice freeboard data improves the simulated sea-ice thickness field. Using real ice concentration data enhances the model realism in both hemispheres. Assimilation of ice concentration data significantly improves the total hemispheric sea-ice extent all year long, especially in summer. Combining the assimilation of ice freeboard and concentration data leads to better ice thickness, but does not further improve the ice extent. Moreover, the improvements in sea-ice thickness due to the assimilation of ice freeboard remain visible well beyond the assimilation periods.
\end{abstract}

\section{Introduction}

Even though sea-ice is an important component of the global climate system, it has been observed only rather recently. Sea-ice observations are mainly limited to sea-ice concentration (the relative amount of area covered by ice, compared to some reference area), to ice drift (displacement of a seaice field) and, recently, to total sea-ice freeboard (height of the top of snow or sea-ice above sea level, hereafter called ice freeboard) and thickness. Ice concentration and drift have been observed at large scale since the late 1970s, in both the Arctic and Antarctic regions, using passive microwave sensors on board satellites (e.g. Gloersen et al., 1992). Comparatively, ice thickness observations are much sparser, hampering a proper estimate of the ice volume. Originally, they stemmed only from upward-looking sonar by submarines in the Arctic (Rothrock et al., 2008) and ship-based visual observations in the Southern Ocean (Worby et al., 2008).

The launch of the Ice, Cloud, and land Elevation Satellite (ICESat) in 2003 with laser altimeter system was therefore a valuable addition to the previous sea-ice observing capabilities. This satellite has shown potential for estimating ice freeboard, which may, when combined with snow depth estimates, be used to retrieve sea-ice thickness (Kwok and Cunningham, 2008) in the Arctic. Measuring campaigns have been restricted to March-April and OctoberNovember (Kwok et al., 2007). However, sea-ice predictability is likely to reside partly in its thickness. Therefore, an accurate knowledge of the sea-ice thickness field is required to 
understand and predict the sea-ice evolution, at least up to 3-5 yr (Blanchard-Wrigglesworth et al., 2011).

To complete the sketch outlined by the sea-ice observations, another source of information is provided by regional or global ocean-sea-ice general circulation models. These models produce consistent fields useful to document and to understand the mean state and variability of sea-ice over the last few decades (e.g. Fichefet et al., 2003; Rothrock and Zhang, 2005). However, the ability of models to accurately simulate the variability as well as summer features of the ice cover remains limited (e.g. Massonnet et al., 2011).

Those model results and observations could be combined to improve sea-ice state estimates using data assimilation techniques. Different data assimilation techniques have been applied to coupled ocean-sea-ice models, assimilating ice concentration (Lisaeter et al., 2003; Lindsay and Zhang, 2006) and drift (Stark et al., 2008) data in the Arctic. However, no attention has been paid to the Southern Ocean region and to ice freeboard data assimilation. Consequently, the main objective of this study is to discuss first the impact of sea-ice concentration data assimilation in both hemispheres, and second, ice freeboard data assimilation. To do so, we have incorporated an ensemble Kalman filter (EnKF) system in the global coupled ocean-sea-ice model NEMOLIM2 (Madec, 2008). Since improving sea-ice drift does not impact on ice concentration significantly (e.g. Stark et al., 2008), ice drift is not assimilated here.

Data assimilation techniques can open many perspectives. For example, it has become possible to realise a reconstruction of sea-ice over the last $40 \mathrm{yr}$, which could be of great interest for process studies. Furthermore, realistic current seaice states could be obtained to initialise operational forecast models as well as climate prediction systems. In this study, we will focus only on the method and not on the applications.

Section 2 describes the ocean-sea-ice model. Section 3 gives a brief overview of the EnKF method. The data used for this work is described in Sect. 4. In Sect. 5, we present what improvements can be expected using ice freeboard data assimilation by showing results using synthetic (modelgenerated) data. In Sect. 6, the impact and benefit of real seaice concentration and ice freeboard data assimilation are discussed. Our conclusions are drawn in the final section.

\section{Model description and validation}

All the simulations analyzed in this study are performed with the global ocean modelling system NEMO $^{1}$ (Madec, 2008) including LIM2 ${ }^{2}$ (Fichefet and Morales Maqueda, 1997) as sea-ice component. This section briefly describes the model, the configuration and the atmospheric forcings.

\footnotetext{
${ }^{1} \mathrm{NEMO}=$ Nucleus for European Modelling of the Ocean

${ }^{2}$ LIM = Louvain-la-Neuve sea ice Model
}

\subsection{Model setup}

\subsubsection{The ocean model}

The ocean model is OPA $9^{3}$, a free surface, primitive equation ocean general circulation model. The grid, named ORCA2, is common to both ocean and sea-ice models. It has a nominal, nearly isotropic, horizontal resolution of $2^{\circ}(110 \mathrm{~km}$ at $60^{\circ} \mathrm{N}$ and $90 \mathrm{~km}$ at the North Pole). The vertical discretization includes 31 levels, with higher resolution near the surface $(10 \mathrm{~m})$ than below $(500 \mathrm{~m}$ at $5500 \mathrm{~m}$ depth). Surface boundary layer mixing and interior vertical mixing are parameterized according to a turbulent kinetic energy closure model (see NEMO reference manual; Madec, 2008). The bottom boundary layer parametrization is based on Beckmann and Döscher (1997). More details can be found in the NEMO reference manual (Madec, 2008).

\subsubsection{The sea-ice model}

The sea-ice model is LIM2, a large-scale dynamicthermodynamic model designed for climate studies. The thermodynamic component of LIM2 is the Semtner (1976) three-layer model. The temperature profile of the snow-ice system is computed by a one-dimensional heat diffusion equation, resolved using one snow layer and two sea-ice layers. Vertical snow and sea-ice growth and melt rates are derived from the energy budgets at the upper and lower interfaces of the snow-ice system. Open water is taken into account using ice concentration as a prognostic variable. Within the ice pack, heat budget allows computing ice growth in open water. Parameterizations of the most relevant seaice physical processes are included (brine pockets, lateral melting, effective heat conduction due to unresolved subgridscale ice thickness variations, surface albedo, penetration of radiation through the ice, snow ice formation). The velocity field is determined from a momentum balance considering sea-ice as a two-dimensional viscous-plastic continuum in dynamical interaction with atmosphere and ocean (Hibler, 1979). More details on LIM2 can be found in Fichefet and Morales Maqueda (1997).

\subsubsection{Forcing fields and initialization}

Atmospheric forcing fields combine NCEP/NCAR daily reanalysis data of $10 \mathrm{~m}$ wind speed and $2 \mathrm{~m}$ temperature (Kalnay et al., 1996) with monthly climatologies of relative humidity (Trenberth et al., 1989), total cloudiness (Berliand and Strokina, 1980) and precipitation (Xie and Arkin, 1997). A quadratic bulk formula with a drag coefficient of $1.4 \times$ $10^{-3}$ is applied to compute the surface wind stress. The downwelling shortwave radiation, the net longwave radiation and the turbulent sensible and latent heat fluxes are computed following empirical parameterizations described in Goosse

\footnotetext{
${ }^{3} \mathrm{OPA}=$ Ocean PArallélisé
} 

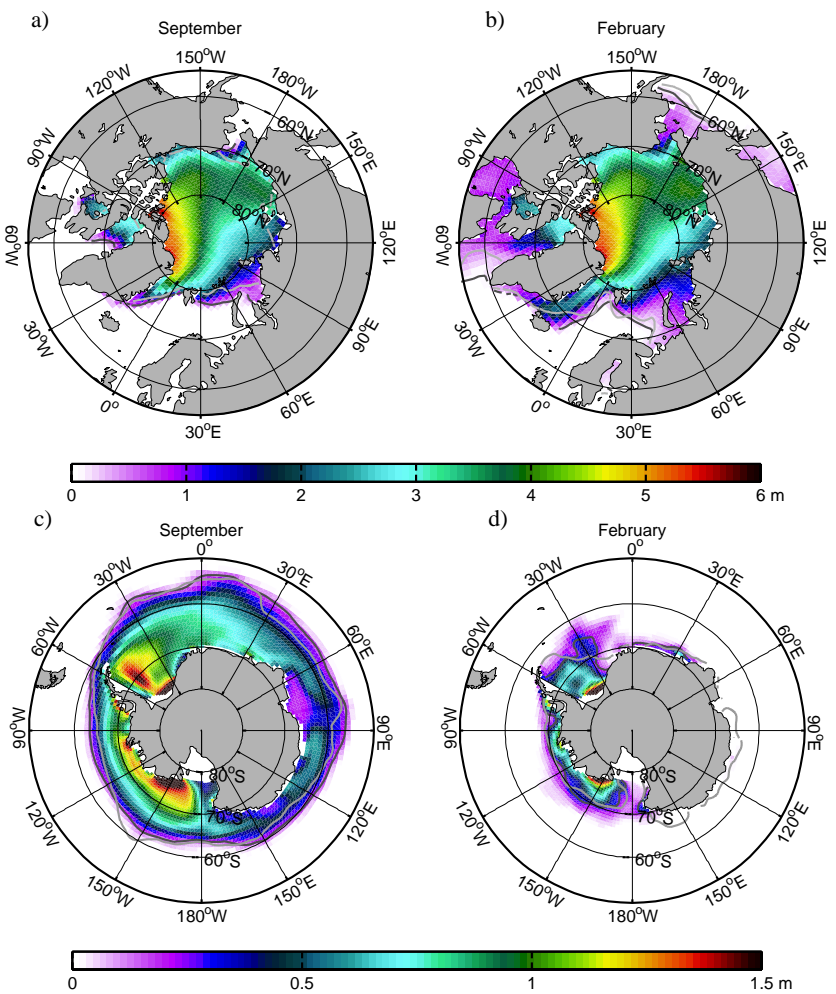

Fig. 1. Simulated mean sea-ice thickness (1979-2005) in September (a, c) and in February $(\mathbf{b}, \mathbf{d})$ in the NH $(\mathbf{a}, \mathbf{b})$ and $\mathrm{SH}(\mathbf{c}, \mathbf{d})$. The dark and light grey lines correspond to the simulated and observed sea-ice edges ( $15 \%$ limit), respectively. Observations come from OSISAF (Eastwood et al., 2010).

(1997). Evaporation/sublimation is derived from the latent heat flux. River runoff rates are prescribed from the climatological dataset of Baumgartner and Reichel (1975) combined with a mean seasonal cycle derived from the Global Runoff Data Centre data (GRDC, 2000). To avoid spurious model drift, a weak restoring of sea surface salinity towards the seasonal Polar Science Center Hydrographic Climatology (PHC; Steele et al., 2001) is applied. The time scale selected for salinity restoring is $1 \mathrm{yr}$.

The spin-up run (named REF), used to initialize all the assimilation experiments, covers the period 1960-2007. Initial conditions of temperature and salinity are based on the PHC climatology for REF simulation. Ice is assumed to be initially present where the sea surface temperature is below $0{ }^{\circ} \mathrm{C}$. Initial snow depth and ice thickness are 0.5 and $3 \mathrm{~m}$ in the Northern Hemisphere (NH) and 0.1 and $1 \mathrm{~m}$ in the Southern Hemisphere (SH).

\subsection{Model performance without data assimilation}

Figure 1 shows the simulated mean sea-ice thicknesses and compares the mean sea-ice extent in February and September to the corresponding observations from the Ocean and SeaIce Satellite Application Facility (OSISAF, Eastwood et al.,
2010) for both the NH and the SH over 1979-2005. Our results are similar to those from simulations performed with an earlier version of the model (Timmermann et al., 2005) in both hemispheres, as detailed below.

\subsubsection{Northern Hemisphere}

The seasonal cycle of ice extent simulated by the model in the $\mathrm{NH}$ is rather close to the observed one (Fig. 1a and b). However, in September (Fig. 1a), the ice extent appears somewhat overestimated. Sea-ice protrudes too far southwards in the Baffin Bay and in the Barents and Kara Seas. Furthermore, a comparison (not shown) with submarine (Rothrock et al., 2008) and satelite ice thickness estimates (Kwok and Cunningham, 2008; Kwok et al., 2009) indicates that the model largely overestimates the sea-ice thickness by about $\sim 2 \mathrm{~m}$ in the East Siberian Sea, in the Laptev Sea and in the Beaufort gyre and by about $0.5 \mathrm{~m}$ in the Kara Sea and near the North Pole. In the Canadian Basin, the ice thickness is overestimated by $0.5 \mathrm{~m}$. As in Timmermann et al. (2005), the winter sea-ice thickness overestimation and the summer melting underestimation are related to each other. Note that the ice thickness overestimation in the Beaufort, East Siberian and Laptev Seas are also present in another recent study with another model, forcing and resolution (Uotila et al., 2012).

The modelled winter sea-ice thickness field in the Arctic (Fig. 1b) features a pronounced gradient from about $\sim 2 \mathrm{~m}$ in the western Siberian Sea to $\sim 4 \mathrm{~m}$ at the North Pole and $\sim 6 \mathrm{~m}$ along the Canadian Archipelago, in agreement with previous simulations with ORCA2-LIM2 (Timmermann et al., 2005) and with other modelling studies (Vancoppenolle et al., 2009; Hunke, 2010). Results of the model from Arctic Ocean Model Intercomparaison Project (AOMIP) also indicate similar behaviour. Johnson et al. (2012) demonstrate that the models overestimate thickness of ice thinner than $2 \mathrm{~m}$ and underestimate the thickness of measured ice thicker than $2 \mathrm{~m}$.

\subsubsection{Southern Hemisphere}

In the austral winter (Fig. 1c), the simulated sea-ice edge agrees relatively well with observations. Besides, the simulated summer minimum ice extent is too small around Antarctica (Fig. 1d). The sea-ice does not extend far enough northwards along the eastern side of the Antarctic Peninsula and sea-ice is absent in the model off East Antarctica.

The mean simulated Antarctic winter sea-ice thickness is $0.6 \mathrm{~m}$. This value is close to the ASPeCt climatology (not shown), which stems from visual ship-based observations (Worby et al., 2008). In the western Ross Sea, the ice thickness is smaller than the circumpolar average, which is consistent with observations in this sector (Jacobs and Comiso, 1989).

In February (Fig. 1d), the opening of the Ross Sea is well reproduced by the model. A tongue of thick ice (maximum thickness about $1.5 \mathrm{~m}$ ) is simulated from the Amundsen 
Sea to the eastern Ross Sea, as in the ASPeCT climatology. Along the eastern side of the Antarctic Peninsula, the modelled ice thickness is greater than in the rest of the pack, as observed. Nonetheless, the ice thickness there appears underestimated by more than $2 \mathrm{~m}$ during both winter and summer, compared to both the ASPeCt climatology and satellite freeboard-based ice thickness estimates (Zwally et al., 2008). This is clasically attributed to a poor representation of the cold barrier winds along the Antarctic Peninsula in the forcing fields (Timmermann et al., 2005; Vancoppenolle et al., 2009; Massonnet et al., 2011).

This brief overview identifies of a number of shortcomings in the results of the control run conducted with the model, which are consistent with earlier studies. The discussion above demonstrates, however, that the model shows a sufficiently good agreement with the seasonal behaviour of sea-ice cover in both hemispheres to permit a sound study of the effect of sea-ice concentration and ice freeboard data assimilation.

\section{The ensemble Kalman filter}

The EnKF is a sequential data assimilation technique that approximates state estimation error statistics by using an ensemble of model runs. The method is fully described in Evensen (1994, 2003). A fully non-linear model is used to propagate the model error statistics. Gaussian error distributions are, however, still assumed for the analysis as in Lisaeter et al. (2003, 2007). However, for many modelled variables, this hypothesis is not necessarily realistic, particularly in the case of sea-ice.

As we apply a sequential data assimilation, each ensemble member is first propagated up to the next time data are available (once a day in our case). This is called the "forecast" step. Then, the data are used in the analysis step to correct the forecast by adding a term proportional to the misfit between observations and the forecast, as explained in Sect. 3.1. This ensemble of analyses is then again propagated forward in time until the next analysis step.

Our version of the EnKF is based on the code developed by the Nansen Environmental and Remote Sensing Center, and described in Burgers et al. (1998). We use the localized analysis presented in Sakov and Bertino (2010) to address the limitations stemming from the relatively small size of our ensemble (25 members) compared to the size of the state space. The localization radius applied in this study is $800 \mathrm{~km}$. This method reduces the spatial domain of influence of observations during the update. Without localized analysis, there are spurious correlations between distant and not physically connected state vector elements (e.g. Houtekamer and Mitchell, 2001; Keppenne and Rienecker, 2002; Anderson, 2007) due to the failure of an ensemble to adequately span the model sub-space (Oke et al., 2007).
The analysis update is calculated in the ensemble space (Hunt et al., 2007). This technique does not permit observational errors to be correlated; so, we assume independent observational errors. Advantages of this technique are to reduce the cost of the EnKF and avoid scaling issues among different variables. This EnKF scheme is more commonly known as a local Ensemble Transform Kalman Filter.

\subsection{Formulation of the EnKF}

The analysis step for the EnKF consists of the following updates performed on each of the ensemble members:

$\boldsymbol{x}_{j}^{a}=\boldsymbol{x}_{j}^{f}+\mathbf{K}\left(\boldsymbol{d}_{j}-\mathbf{H} \boldsymbol{x}_{j}^{f}\right)$.

The control vector $\boldsymbol{x}_{j} \in \mathbb{R}^{n \times 1}$ contains all the relevant variables (i.e. all two-dimensional and three-dimensional oceanic variables and all sea-ice variables except sea-ice temperature and heat content) on all grid points of the model for the $j$ th members of the ensemble. The sea-ice heat content and temperature are largely non-linear (L distribution, Lisaeter et al., 2003). An update of their fields by EnKF leads to nonphysical behaviour (large melting/formation rate) during the first step of the forecast. Therefore, we decided to exclude these variables from the control vector. $n$ is the dimension of the control vector for each ensemble member. $x_{j}^{a}$ is the analyzed state and $\boldsymbol{x}_{j}^{\mathrm{f}}$ is the forecast state, while $\boldsymbol{d}_{j} \in \mathbb{R}^{p \times 1}$ is a vector containing the $p$ available observations at that time for the $j$-th members of the ensemble. The observations used for the $j$-th member are perturbed according to the uncertainties in the measurements: $\boldsymbol{d}_{j}=\boldsymbol{d}+\boldsymbol{\epsilon}_{j}$, where $\boldsymbol{d}$ is the unperturbed observation vector and $\boldsymbol{\epsilon}_{j}$ the perturbation for the $j$-th ensemble member. The operator $\mathbf{H} \in \mathbb{R}^{p \times n}$ projects the model state into the observational space. This projection ranges from a simple interpolation onto the observational grid to complex transformations of the model variables to some observed quantities. $\mathbf{K}$ is called the "Kalman gain matrix":

$\mathbf{K}=\mathbf{P}_{\mathrm{e}}^{\mathrm{f}} \mathbf{H}^{T}\left(\mathbf{H P}_{\mathrm{e}}^{\mathrm{f}} \mathbf{H}^{T}+\mathbf{R}_{\mathrm{e}}\right)^{-1}$,

$\mathbf{R}_{\mathrm{e}} \in \mathbb{R}^{p \times p}$ is an approximation of the observation error covariance matrix. $\mathbf{P}_{\mathrm{e}}^{\mathrm{f}} \in \mathbb{R}^{n \times n}$ is an approximation of the model forecast error covariance matrix. The covariance matrix is approximated because the full error covariance matrix for observations is poorly known, and - for the model - the matrix is too large to be computed explicitly in oceanographic applications. The EnKF approximates it by an ensemble of model states $\mathbf{E} \in \mathbb{R}^{n \times m}$, where $m$ is the number of members in the ensemble. The ensemble of anomalies $\mathbf{A} \in \mathbb{R}^{n \times m}$ is defined as

$\mathbf{A}=\mathbf{E}\left(\mathbf{I}-\frac{1}{m} \mathbf{1 1}^{T}\right)$,

where $\mathbf{1}$ is a vector with all elements equal to one and $\mathbf{I}$ is the identity matrix. The approximated error covariance matrix $\mathbf{P}$ 
is then

$\mathbf{P}_{\mathrm{e}}^{\mathrm{f}}=\frac{1}{m-1} \mathbf{A} \mathbf{A}^{T}$

Since the assimilation scheme is multivariate, both ocean and sea-ice variables are updated in the analysis step. As a Gaussian distribution of errors is assumed for sea-ice variables, this can lead to non physical states. Consequently, we verify that the sea-ice concentration and thickness as well as snow thickness are non-negative everywhere (otherwise they are set equal to zero). Furthermore, we impose a maximum value of 1 for sea-ice concentration. Also, note that the EnKF is not associated with any freshwater or salt flux towards the ocean. Thus, the EnKF could be a potential mass sink/source in the system. Finally, the sea surface temperature is constrained to be greater or equal to the freezing temperature.

\subsection{Ensemble generation}

The initial conditions for all the members are provided by the REF simulation without perturbation. Perturbations only apply to the wind fields. Winds are particularly important for both the sea-ice motion and surface heat in both hemispheres (Watanabe and Hasumi, 2005; Bitz et al., 2002). Consequently, to generate the ensemble of model states (25 members in our case), we have chosen to perturb only the wind forcing. As the surface fluxes are computed by the CLIO atmospheric bulk formulae in our experiments, a perturbation of the wind field affects both the momentum and heat fluxes. This ensures the dispersion of our ensemble.

\subsubsection{Wind perturbation}

To create a perturbed wind forcing field that is consistent with the spatial structure of the variability of observations, we selected an approach based on the covariance of the data. We started by gathering samples of data (wind fields in our case) at discrete times. The samples should be sufficiently different so that we could assume the data were not correlated. The sampled data were arranged in a matrix $\mathbf{Y} \in \mathbb{R}^{m \times n}$, where $m$ is the total number of samples and $n$ is the size of each sample (also called the state vector). In the case of our two-dimensional wind field, $n$ is $n_{x} \times n_{y}$, where $n_{x}$ and $n_{y}$ are the number of grid points along the $x$ - or $y$-directions, respectively. We extracted the wind field every 11 days, starting on 6 January, for 1950 to 2008, inclusive. This gave us a total of $m=1947$ atmospheric states that we assumed to be independent of each other. As a next step, we found the mean state and subtracted it from each row in $\mathbf{Y}$, thus creating the matrix of anomalies $\mathbf{X}$. The covariance matrix $\Sigma \in \mathbb{R}^{n \times n}$ could directly be constructed using $\mathbf{X} \in \mathbb{R}^{m \times n}$ or - to save space and to speed up computations - using $\mathbf{R}_{\mathrm{p}} \in \mathbb{R}^{m \times n}$ obtained from a $\mathrm{QR}$-decomposition of $\mathbf{X}=\mathbf{Q} \mathbf{R}_{\mathrm{p}}$ as presented:
$\boldsymbol{\Sigma}=\frac{1}{m} \mathbf{X}^{T} \mathbf{X}=\frac{1}{m} \mathbf{R}_{\mathrm{p}}^{T} \mathbf{Q}^{T} \mathbf{Q} \mathbf{R}_{\mathrm{p}}=\frac{1}{m} \mathbf{R}_{\mathrm{p}}^{T} \mathbf{R}_{\mathrm{p}}$,

where $\mathbf{Q} \in \mathbb{R}^{m \times m}$ is an orthogonal matrix.

Therefore, a random perturbation $\boldsymbol{P} \in \mathbb{R}^{n \times 1}$ with the same covariance properties as the original data could be created as follows:

$\boldsymbol{P}=\sqrt{\frac{1}{m}} \mathbf{R}_{\mathrm{p}}^{T} z$

where each element of $z \in \mathbb{R}^{m \times 1}$ is sampled from the normal distribution $\mathcal{N}(0,1)$. To create a perturbed wind field state for a particular ensemble member on that day $\boldsymbol{x}_{\mathrm{p}}$, one has to add the original wind field state $\boldsymbol{x}_{\mathrm{o}}$ to the perturbation $\boldsymbol{P}$ to get $\boldsymbol{x}_{\mathrm{p}}=\boldsymbol{x}_{\mathrm{o}}+\alpha \boldsymbol{P}$. In our case, $\boldsymbol{x}_{\mathrm{o}}$ is the original wind field of a day, $\boldsymbol{x}_{\mathrm{p}}$ the perturbed wind field and $\alpha$ a scale factor.

We computed separate covariance matrices $\mathbf{R}_{\mathrm{p}}$ for the zonal and meridional components of the wind field. Nevertheless, to create consistent wind field perturbations, we used the same perturbation vector $z$ for the two components. The scale factor $\alpha$ selected here is 0.5 . We did not assume any temporal correlation between the perturbations. However, the model smooths the effect of the perturbation. This leads to an effective scale factor lower than 0.5 (not diagnose here). It is worth mentioning that no inflation was applied to enlarge the spread of the ensemble.

\section{Description of the assimilated data}

\subsection{Synthetic observation data}

In order to evaluate the potential of the EnKF data assimilation system in a controlled framework, we first assimilated synthetic sea-ice data. The synthetic dataset was extracted from a simulation with perturbed forcing, supposedly representing sea-ice observations. The snow, ice and water densities were taken equal to $330.0 \mathrm{~kg} \mathrm{~m}^{-3}, 915.1 \mathrm{~kg} \mathrm{~m}^{-3}$ and $1023.9 \mathrm{~kg} \mathrm{~m}^{-3}$, respectively. Localization in time and space are the same as the real sea-ice data described in the next part. To ensure that the EnKF will correct the model ensemble when using real observations, the synthetic data have to be built in such a way that the bias between synthetic data and model output is similar to or larger than the bias between real observations and model output. So, the synthetic data have been built as for the REF simulation but with the DRAKKAR forcing set 4 (DFS4) described in Brodeau et al. (2010) instead of the NCEP/NCAR forcing set. The simulated ice extent and thickness are underestimated with the DFS4 atmospheric forcing in both hemispheres (not shown), thus the bias between the model ensemble and synthetic data are larger, in both hemispheres, than in the case where real sea-ice observations are used (comparison of green lines in Figs. 2 and 3). The uncertainties in the synthetic observations are identical to the ones of the real observations. 

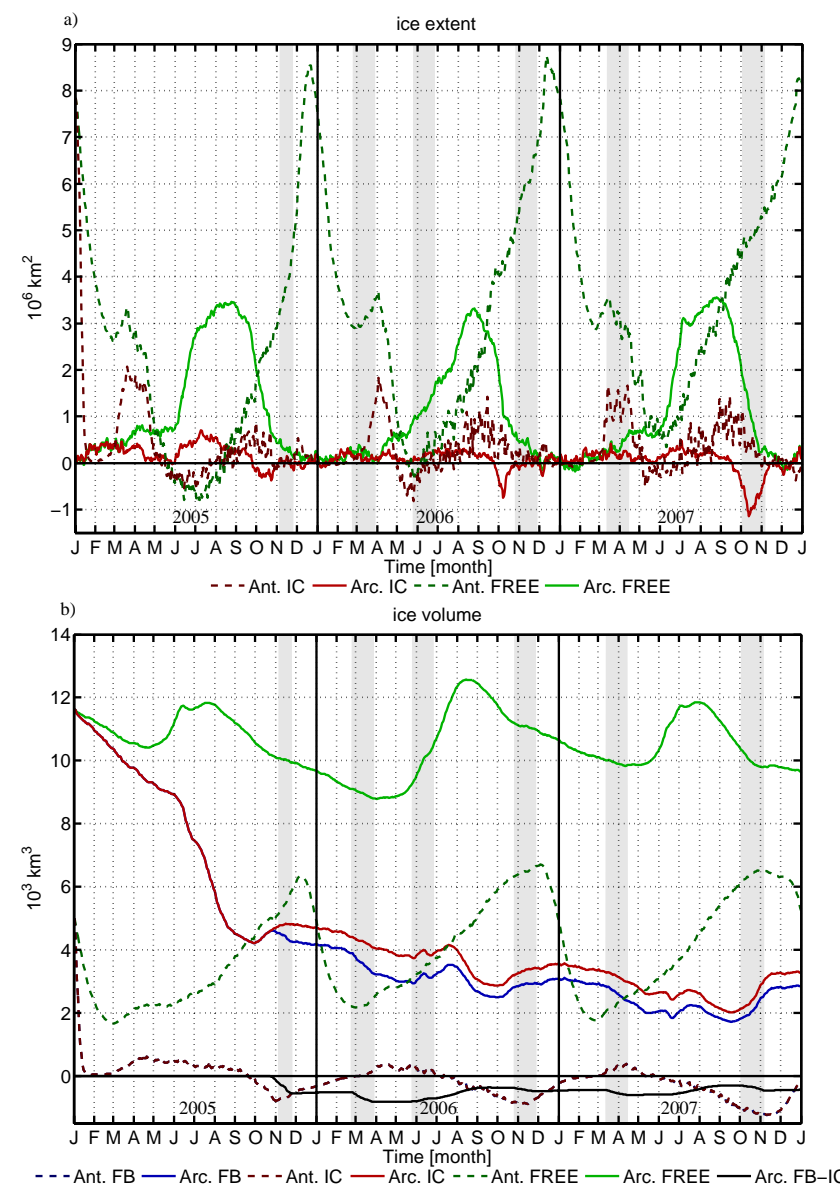

Fig. 2. Time series of the sea-ice extent (top) and volume (bottom) difference compared to synthetic observations for both the NH (full lines) and the SH (dashed lines) over 2005-2007. Green lines represent the FREE run difference, red lines the IC run difference, blue lines the FB run difference and black line the FB-IC difference. Grey shading areas indicate periods when the ice freeboard data are available.

\subsection{Real observational data}

\subsubsection{Sea-ice concentration}

The sea-ice concentration data used in this study come from the OSISAF framework (Eastwood et al., 2010), which provides data and their uncertainties at daily frequency. OSISAF sea-ice concentrations derive from the multi-channel microwave brightness temperatures collected by two satellite instruments: the Scanning Multichannel Microwave Radiometer (SMMR) (1979-1987) and the Special Sensor Microwave/Imager (SSM/I) (1987-2007) (Gloersen et al., 1992; Cavalieri et al., 1997). The nominal resolution of this product is $12.5 \mathrm{~km}$. To avoid indirect data, we excluded gap areas filled through extrapolation (missing orbit, missing scan lines and polar observation hole) as well as areas where a coastal correction is applied. For our analysis, to limit com-
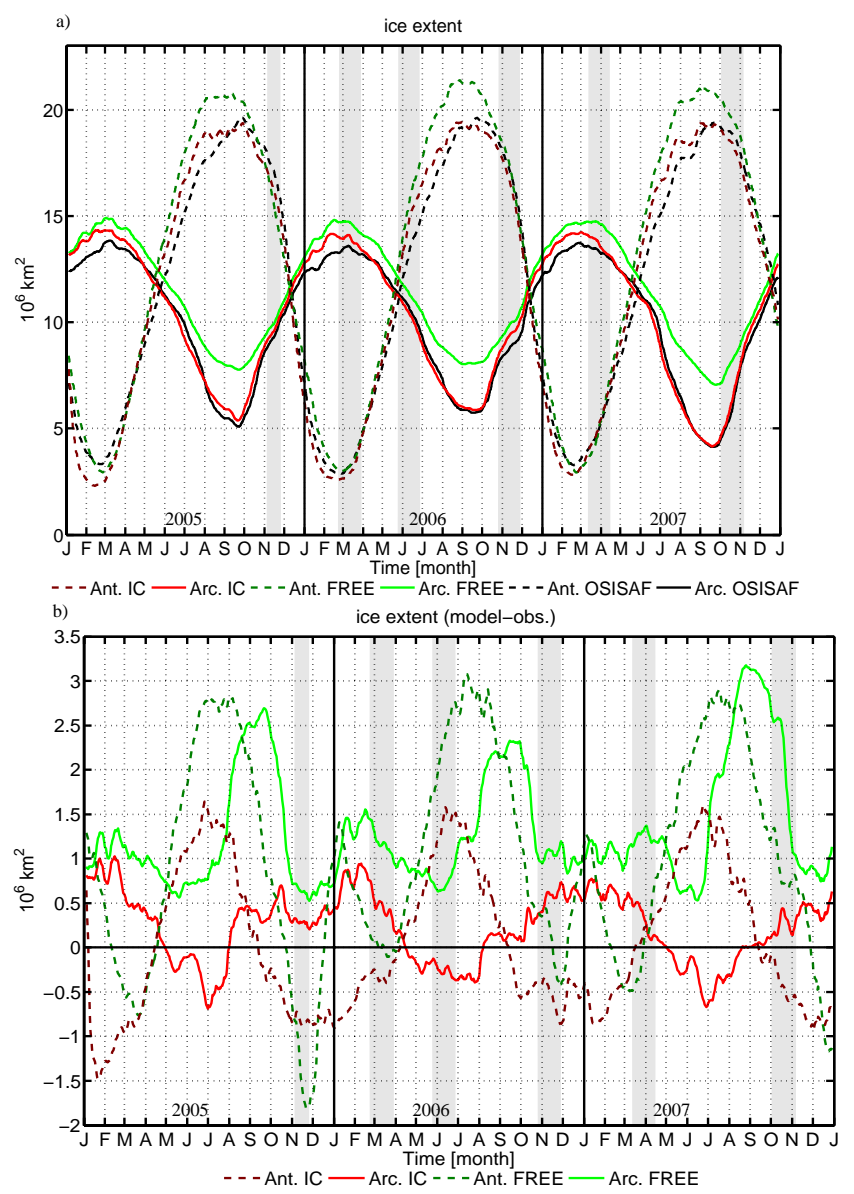

Fig. 3. Times series of sea-ice extent over 2005-2007 (a). The observations are in black. The red lines correspond to the IC run and the green lines to the FREE run. The dashed lines are for the NH and the solid lines for the SH. (b) Differences between model and observations are plotted with the same codes. Grey shading areas indicate periods when the ice freeboard data are available. A one week smoothing is apply on both figures.

putational costs, data were interpolated on the model grid using a bilinear interpolation scheme. The uncertainties in seaice concentration vary in time and in space. During summer, the error was estimated up to $20 \%$, while during winter the deviation between ice concentration measurements and ice charts are around $10 \%$. Close to the ice edge or in areas with very compact sea-ice (sea-ice concentration of about $100 \%$ ), the uncertainties are lower, about $7 \%$, throughout the year.

\subsubsection{Total sea-ice freeboard}

The total sea-ice freeboard (hereafter called ice freeboard) is the sum of snow depth and sea-ice freeboard. Ice thickness can be derived from it if snow depth and density are known. Kwok and Cunningham (2008) estimated the latter using Advanced Microwave Scanning Radiometer (AMSR) sea-ice motion fields, European Centre for Medium-Range 
Table 1. ICESat Campaigns available from the National Snow Ice Data Center.

\begin{tabular}{llc}
\hline Campaign name & Period & Span in days \\
\hline ON05 & 4 Nov to 24 Nov 2005 & 21 \\
FM06 & 22 Feb to 27 Mar 2006 & 34 \\
MJ06 & 24 May to 26 June 2006 & 34 \\
ON06 & 25 Oct to 27 Nov 2006 & 34 \\
MA07 & 12 Mar to 14 Apr 2007 & 34 \\
ON07 & 2 Oct to 5 Nov 2007 & 37 \\
\hline
\end{tabular}

Weather Forecasts (ECMWF) snow accumulation and a seasonal climatology of snow density (Warren et al., 1999). As the determination of snow parameters carry substantial uncertainties, it is recommended to directly assimilate ice freeboard into the model.

The ice freeboard data used in this study was provided by the National Snow Ice Data Center. These data are available only for the Arctic below $86^{\circ} \mathrm{N}$. The data spanned six ICEsat laser campaigns (see Table 1). Islands, icebergs and land areas were filtered out with a criterion based on large elevation variations (more than $4 \mathrm{~m}$ ) along the track. A zero ice freeboard was assigned to areas where ice concentration is below $20 \%$. This is an empirical limit to avoid the ice freeboard contamination introduced by open ocean water waves. Yi and Zwally (2010) give a complete description of the algorithms used to process the data. As for sea-ice concentration data, ice freeboard data were interpolated on the model grid each day. The uncertainties in ice freeboard data were assumed equal to the standard deviation of all data available in each model grid cell, i.e. $15 \mathrm{~cm}$ on average over all the data points and over all the periods.

\section{Impact of the assimilation of synthetic sea-ice data}

In experiments with synthetic sea-ice data assimilation, all the components of the system are known, in contrast to the real case in which only some observed variables are available. Furthermore, we knew that the unperturbed synthetic observations are compatible with the model physics. As we had access to the true control vector, we were able to evaluate, with those synthetic data, the improvement brought by data assimilation of an observed variable such as ice concentration on the ice volume variable for which adequate observations were missing. We were able to profit by the consequent advantages of assessing the quality of the data assimilation procedure, the sensitivity of ice thickness to assimilation of ice concentration, as well as by the potential improvement due to the assimilation of ice freeboard.
Table 2. Description of the simulations carried out with synthetic observations and real data assimilation.

\begin{tabular}{lll}
\hline Experiment & $\begin{array}{l}\text { sea-ice concentration } \\
\text { (synthetic/real) }\end{array}$ & $\begin{array}{l}\text { Ice freeboard } \\
\text { (synthetic/real) }\end{array}$ \\
\hline FREE & NO & NO \\
IC & YES & NO \\
FB & YES & YES \\
\hline
\end{tabular}

\subsection{Experimental setup}

The assimilation experiments covered the period 2005-2007. An ensemble of 25 members were used. Each member was forced with a slightly different wind field (see Sect. 3.2). Initial conditions for each member were taken from the REF simulation. Assimilated data were the synthetic observations described in the previous section. The assimilation scheme was called each day.

Three experiments were performed (see Table 2):

- "FREE" where winds were perturbed but no data were assimilated;

- "IC" where sea-ice concentration data were assimilated;

- "FB" where both sea-ice concentration and ice freeboard data were assimilated;

The discussion below covers the ensemble means of each simulation.

\subsection{Results}

The FREE simulation shows, in comparison to synthetic observations, large discrepancies in Arctic sea-ice extent (up to 3 millions $\mathrm{km}^{2}$ at the beginning of September, Fig. 2a) and volume (up to $12000 \mathrm{~km}^{3}$ in August, Fig. 2b). In the SH, differences between synthetic observations and FREE are also large (Fig. 2). As expected, IC exhibits a sea-ice extent that is closer to synthetic observations than FREE in NH as well as in SH. The root mean squared error (RMSE) of sea-ice extent decreases by $85 \%$ in IC in the NH, and by $87 \%$ in the SH (Table 3). The RMSE of sea-ice volume also decreases in IC by $66 \%$ in NH and by $88 \%$ in SH compared to FREE. The adjustment of the sea-ice volume ends after the first summer in both the NH and SH (Fig. 2). It is the time needed to transform the excess of multi-year sea-ice still present during summer in FREE (compared to the synthetic observations) in seasonal sea-ice in IC, which corresponds to the synthetic observations.

Assimilating both ice concentration and ice freeboard (FB simulation) does not further affect the ice extent (Table 3 ). This is due to the spatial coverage of ice freeboard data, which do not reach the ice edge (data are automatically excluded if sea-ice concentration is lower than $20 \%$ ). However, the ice volume is improved in FB as compared with 
Table 3. Root mean squared error (RMSE) of sea-ice extent and volume between data assimilation experiments using the synthetic data and the synthetic observations themselves in the $\mathrm{NH}$ and $\mathrm{SH}$, respectively, from the begining of October and February (end of the adjustment phase) to the end of the simulation. Within parentheses are the reductions of RMSE for each simulation (compared to the FREE simulation).

\begin{tabular}{lcc}
\hline Experiment & RMSE (NH) & RMSE (SH) \\
\hline sea-ice extent $\left(\times 10^{6} \mathrm{~km}^{2}\right)$ & & \\
\hline FREE & 1.51 (n.a.) & 3.83 (n.a.) \\
IC & $0.22(-85 \%)$ & $0.51(-87 \%)$ \\
FB & $0.22(-85 \%)$ & $0.51(-87 \%)$ \\
\hline sea-ice volume $\left(\times 10^{3} \mathrm{~km}^{3}\right)$ & & \\
\hline FREE & 10.44 (n.a.) & 4.25 (n.a.) \\
IC & $3.55(-66 \%)$ & $0.49(-88 \%)$ \\
FB & $3.06(-71 \%)$ & $0.49(-88 \%)$ \\
\hline
\end{tabular}

IC in the NH. The RMSE is decreased (as compared with FREE) by $71 \%$ in FB, and $66 \%$ in IC. It is worth noticing that the improvements due to ice freeboard assimilation in October-November and in March-April on sea-ice volume remain throughout the year (Fig. 2). The largest improvements are seen during the two first ice freeboard measurment campaigns (ON05 and FM06). These improvements are accompanied by some discontinuity (Fig. 2) clearly due to the lack of data during several months.

These results show that the data assimilation method brings the modelled ice extent and volume closer to the synthetic data than in the FREE run in both hemispheres (Fig. 2). The next part of this study examines if our conclusions remain valid when using real observations.

\section{Impact of the assimilation of real sea-ice data}

\subsection{Experimental setup}

Two simulations were carried out to highlight the utilily of sea-ice concentration and ice freeboard data assimilation in the case where real observations are used: an experiment with assimilation of real sea-ice concentration data (IC), and a simulation with assimilation of both real sea-ice concentration and ice freeboard data (FB) (Table 2). The reference simulation (FREE) is the same as in the previous section. All these simulations cover the period 2005-2007. The model setup, the initial conditions, the forcing fields, the model parameters, the assimilation method, the ensemble size and the generation of the ensemble were the same as in the experiments conducted with synthetic data (Sect. 5). The only difference between the previous experiments and these ones are the type of data used. In the previous section, the data are synthetic observations, while here real sea-ice concentration and freeboard data are used.
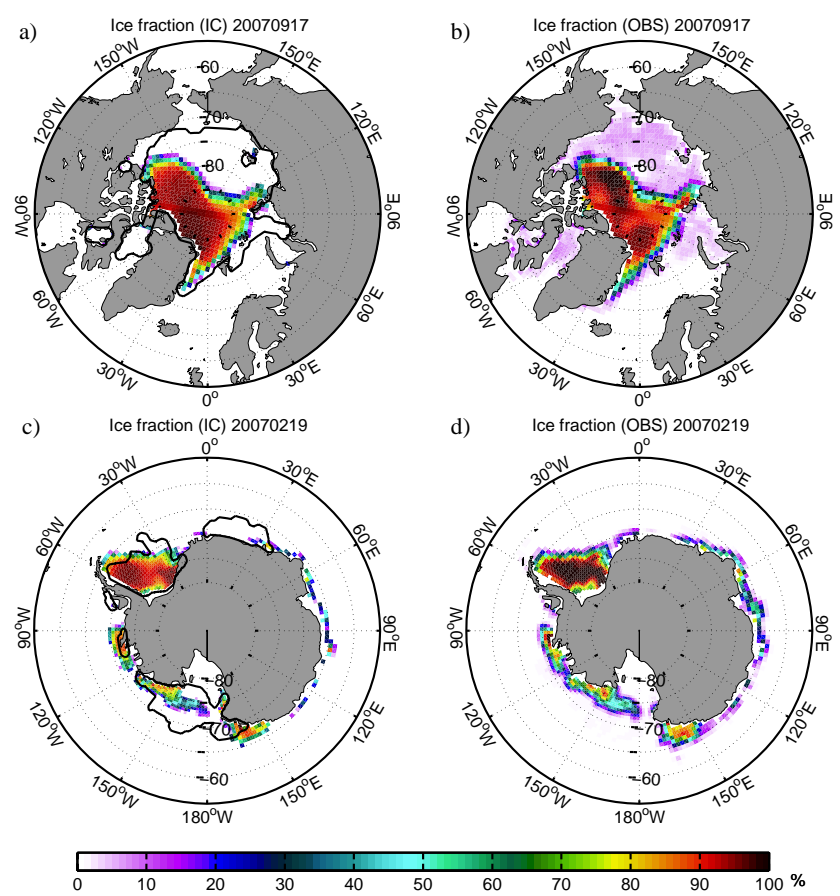

Fig. 4. Sea-ice concentrations during the minimum of sea-ice extent in 2007 in the $\mathrm{NH}(\mathbf{a}, \mathbf{b})$ and $\mathrm{SH}(\mathbf{c}, \mathbf{d})$. Colors show the sea-ice concentration in IC simulation (a, c) and in the OBS $(\mathbf{b}, \mathbf{d})$. The thick black line represents the sea-ice extent in the FREE simulation.

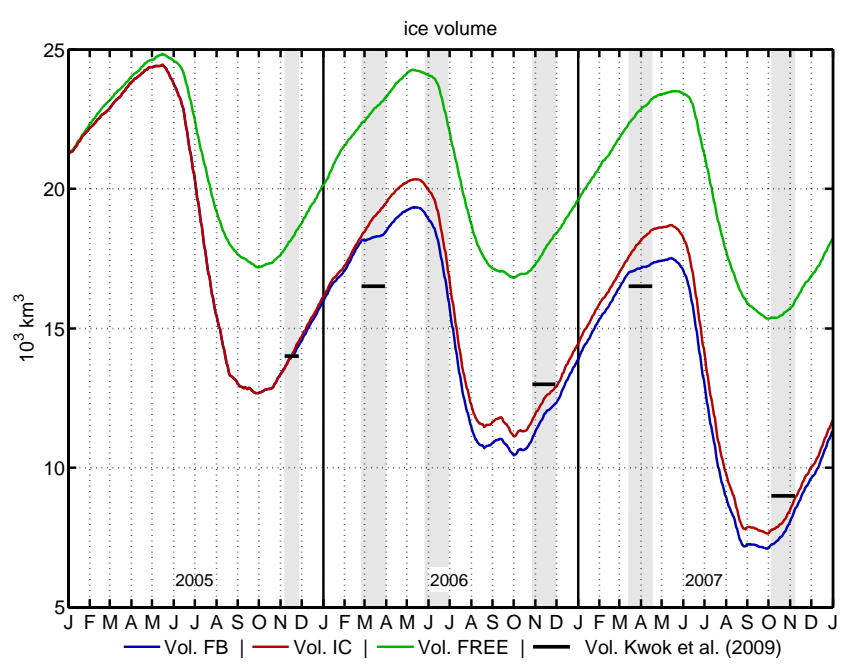

Fig. 5. Time series over 2005-2007 of the sea-ice volume in the Arctic Ocean for the FREE (green line), IC (red line) and FB (blue line) runs. Black lines are the mean sea-ice volumes provided by Kwok et al. (2009). The two sea-ice volume estimates (model and obs) are on the domain used in Kwok et al. (2009) (i.e. the Arctic Ocean). Gray areas indicate the periods when ice freeboard data are available. 

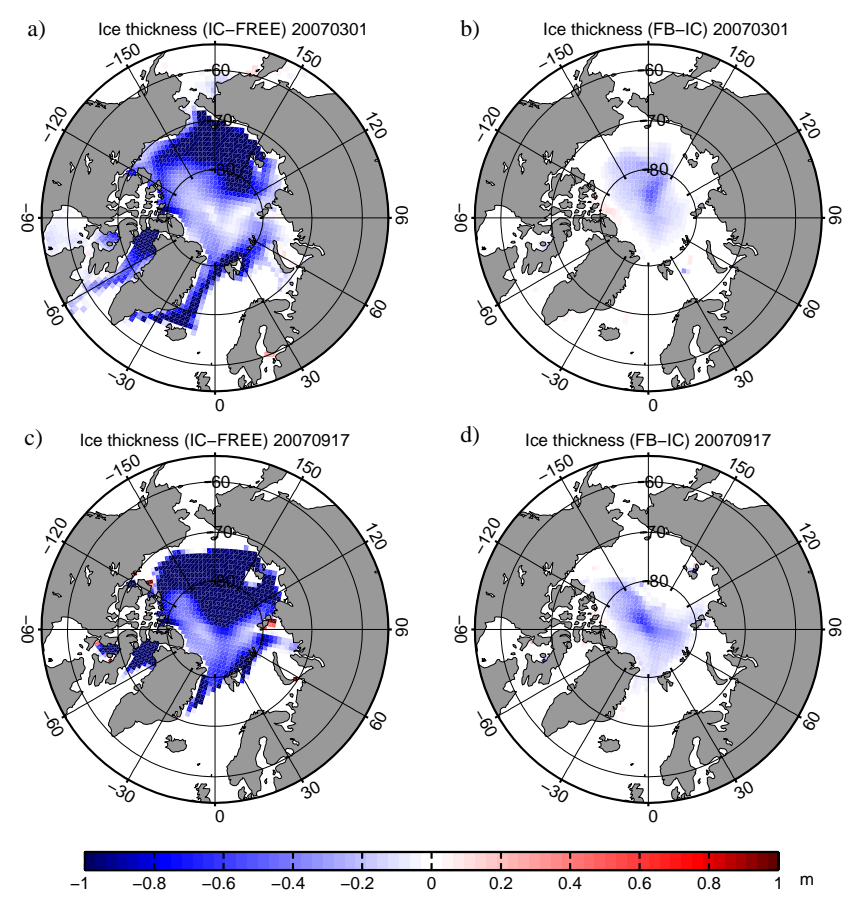

Fig. 6. Sea-ice thickness differences at the 2007 maximum (a, b) and minimum (c, d) sea-ice extent in Arctic. Colors show the seaice thickness differences between FB and IC $(\mathbf{b}, \mathbf{d})$ and between IC and FREE (a, c).

\subsection{Assimilation of real sea-ice concentration data}

\subsubsection{Sea-ice cover in the Northern Hemisphere}

The impact of real data assimilation on sea-ice extent and volume are similar to those obtained with synthetic data. FREE overestimates the mean sea-ice extent, particularly during summer months (Fig. 4) along the Siberian coast and in Baffin Bay. Assimilation of ice concentration data reduces this bias (Figs. 4 and 3) for all seasons, but particularly in summer when the errors of FREE are the largest. During freeze-up, the sea-ice extent in both IC and FREE remain close to each other.

During the first months of 2005 (since May), the Arctic ice volume is similar in IC and FREE (Fig. 5). After the first summer, the sea-ice volume in IC is much lower than in FREE (Fig. 5). This is due to a lowered summer sea-ice extent in IC that induces a large substitution of multi-year seaice (area covered by sea-ice in summer, mainly composed of sea-ice thickness greater than $2.50 \mathrm{~m}$, Fig. 4) present in the Beaufort and East Siberian Seas in FREE by a seasonal seaice (area covered by sea-ice in winter and not in summer, mainly composed of sea-ice thickness lower than $2.50 \mathrm{~m}$ in winter) in IC (Fig. 4a). In October 2005, the total Arctic seaice volume in IC is $5 \times 10^{3} \mathrm{~km}^{3}$ smaller than in FREE ( $40 \%$ of Arctic volume in FREE during summer). As compared with the sea-ice volume estimate from Kwok et al. (2009),
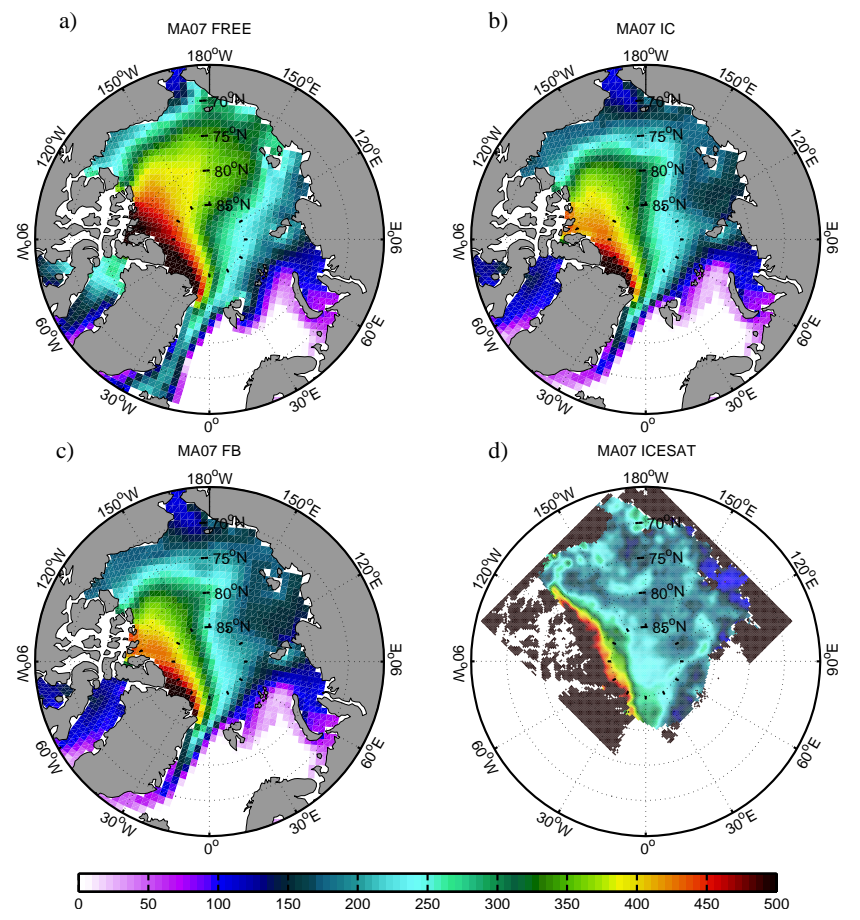

Fig. 7. Sea-ice thickness during the MA07 (March-April) campaign in the FREE, IC and FB runs (a, b, c respectively), and in the observations (d) (Kwok et al., 2009).

after 10 months (end of the first summer in the simulations), IC is clearly better during summer (Fig. 5). This change of sea-ice concentration propagates into the multi-year ice. After three years of simulation, the whole sea-ice pack is affected (Fig. 6a and c). Areas where sea-ice is seasonal in IC and multi-year in FREE show a lower sea-ice thickness in IC (ice thickness differences up to $-2 \mathrm{~m}$ ). In areas where sea-ice is, in both simulations, multi-year (or seasonal), differences are lower in both winter and summer (up to $-0.6 \mathrm{~m}$ ).

Over the entire ice pack during both winter and summer (Figs. 5, 7 and 8), IC reduces the ice thickness overestimation seen in FREE. However, the decrease of ice thickness in IC is too strong along the ice edge, especially during summer in central Arctic (Fig. 8). This is a sign that the model tends to underestimate ice thickness in summer and also to produce a too thin sea-ice during the first winter months on the Siberian side of the Arctic. Several hypotheses can explain this too low ice thickness near the ice edge during summer: either the atmosphere-ice heat flux, as derived from the forcing fields, is overestimated; or the model representation of mass source and sink processes leads to excessive melting. During winter, sea-ice in IC is too thick in the Beaufort Sea. In the rest of the sea-ice pack, sea-ice thickness in IC is very close to observations. However, the sharp sea-ice thickness gradient observed is much weaker north of the Canadian Archipelago in all the experiments. 

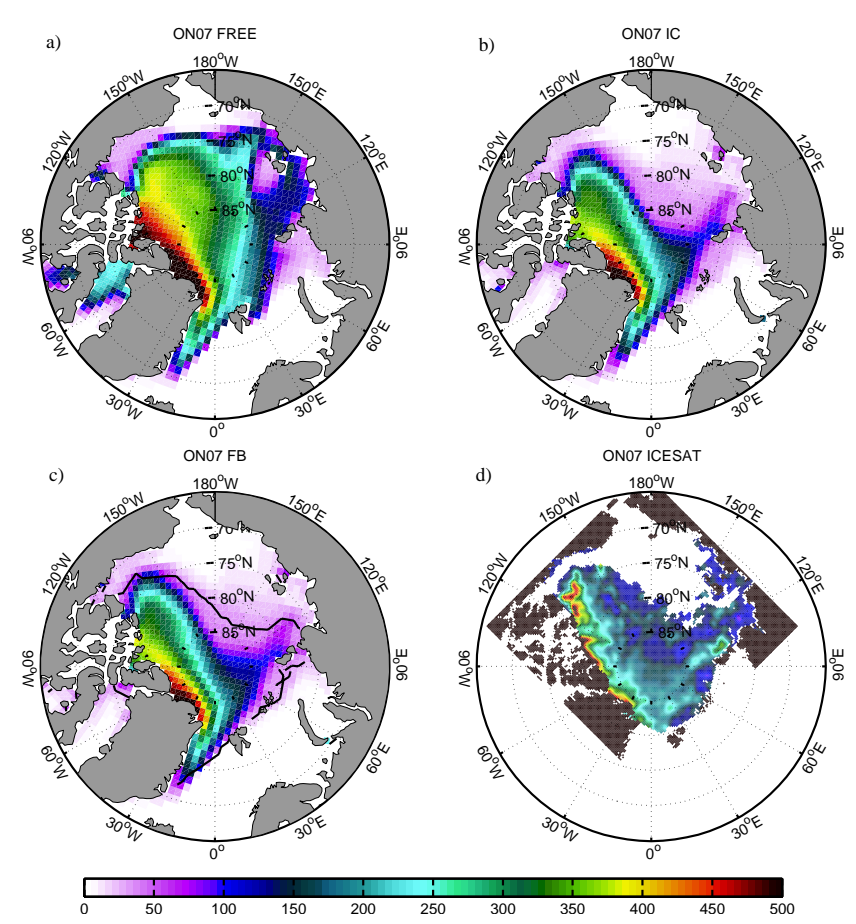

Fig. 8. Sea-ice thickness during the ON07 campaign in the FREE, IC and FB runs (a, b, c respectively), and in the observations (Kwok et al., 2009). The black line corresponds to the sea-ice edge simulated in FB at the minimum extent (17 September 2007).

These changes in sea-ice thickness and extent lead to changes in ice production. Thin ice supports stronger conductive heat fluxes than thick ice (Ebert and Curry, 1993; Maykut, 1986). Therefore, the model produces more sea-ice in IC than in FREE (Fig. 9) in winter. During the melting period, the sea-ice that is thinner in IC than in FREE disappears faster, further enhancing the melting rate because of a more efficient ice-albedo feedback.

As the FREE simulation overestimates the sea-ice extent and thickness during the melting period and in winter, the EnKF tends to keep the model in agreement with observations and to remove the excess of sea-ice. However, between July and September, each year, the EnKF creates sea-ice. This may seem surprising as FREE still has too large an ice extent at this time when the centre of the pack begins to freeze, but the marginal sea-ice zone is still melting. EnKF is producing sea-ice in the entire pack (except in marginal ice zone in Barents Sea) at a rate of about $1 \mathrm{~cm}$ of sea-ice per assimilation step for month of August 2006. This means that the ice does not consolidate fast enough in the pack and melts too fast in the sea-ice edge in the Atlantic sector in NEMOLIM. Causes of this behaviour might be biases in the forcing or a too strong positive ice-albedo feedback during summer.

In the present model setup, the EnKF does not conserve oceanic salt in the model, since the ice-ocean freshwater flux associated with the ice growth/melt induced by the filter is

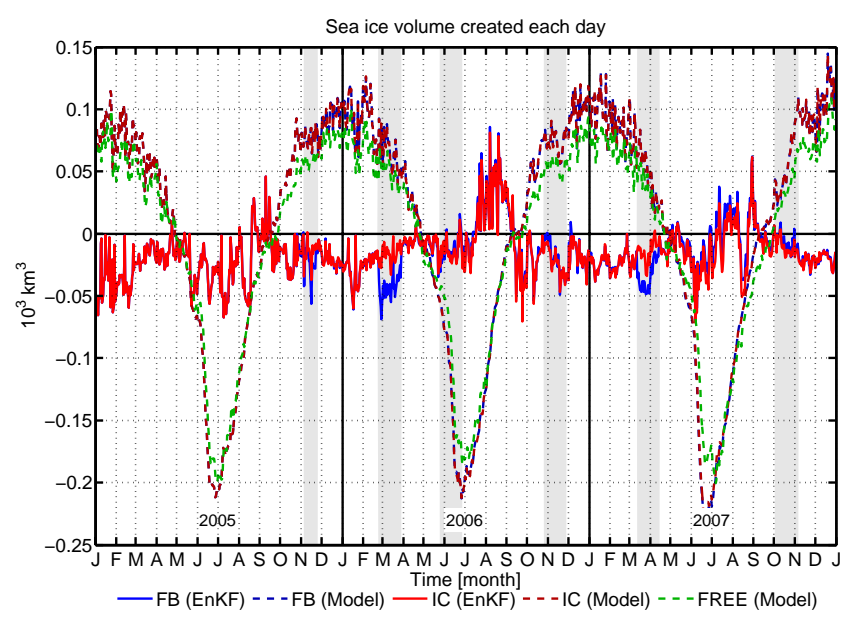

Fig. 9. Times series over 2005-2007 sea-ice volume produced each day in the Arctic by the model (dashed line) and by the EnKF (solid line) for FB (blue), IC (red) and FREE (green). Gray areas indicate the periods when ice freeboard data are available.

not taken into account. Data assimilation leads thus to a net increase in oceanic salt content in IC, as compared to FREE (not shown).

\subsubsection{Sea-ice cover in the Southern Hemisphere}

In the Southern Ocean, FREE overestimates the winter ice extent, while in summer, the agreement with observations is quite good (Fig. 3). However, this agreement in summer is due to a compensation of errors in different regions (Fig. 4c and $\mathrm{d}$ ). There is an excess of sea-ice in the Ross Sea and along Dronning Maud Land Coast and a lack of sea-ice at the tip of the Antarctic Peninsula, along the East Coast of Antarctica and in the Bellingshausen Sea in FREE. Assimilation of ice concentration data corrects all these biases. However, some problems persist. Areas where ice concentrations are low (below $15 \%$ ) are missing in both FREE and IC. Summer ice concentrations below $50 \%$ are almost absent. During freeze-up, the sea-ice extents of both IC and FREE are similar until the end of June. Afterwards, until the end of winter, IC is clearly more realistic than FREE (Fig. 3).

Sea-ice thickness differences between IC and FREE are significant in both winter and summer (Fig. 10). During summer, the ice thickness differences correspond well to the differences in ice edge location (Fig. 4c). During winter, ice thickness is smaller in IC than in FREE almost everywhere $(-30 \mathrm{~cm})$, except in the western Weddell Sea $(+40 \mathrm{~cm})$ and near Pridz Bay $(+20 \mathrm{~cm})$. Timmermann et al. (2004) in a similar model configuration had a lack of sea-ice in these area. However, in the other locations, they found good agreement between the model results and the ASPeCT data (Worby et al., 2008). Therefore, the increase in ice thickness in the Weddell Sea (and Pridz Bay) improves the simulation. In the other areas, sea-ice in IC is too thin. 


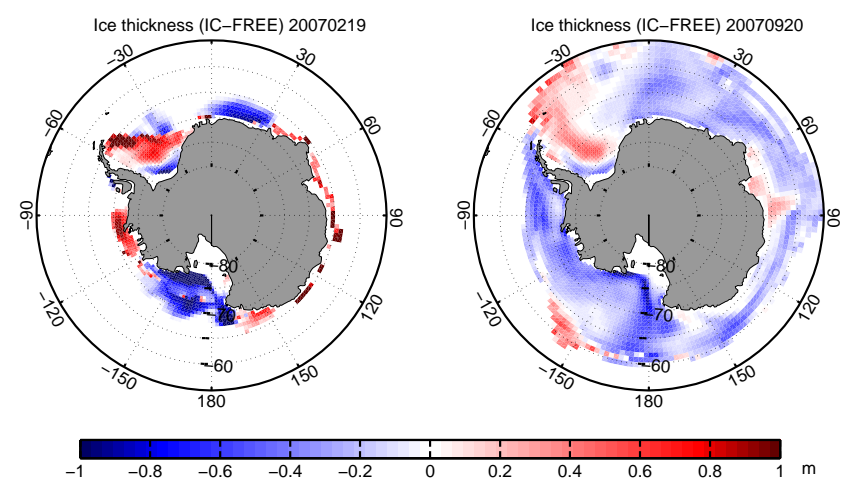

Fig. 10. Sea-ice thickness differences at the time of minimum (a) and the maximum (b) in 2007. Colors show the sea-ice thickness differences between FREE and IC.

\subsubsection{The innovation vector}

Previous sections have demonstrated that the data assimilation method used leads to good agreement between model (IC simulation) and the ice concentration observations (OSISAF). However, the estimation of the model error covariance matrix by the filter (related to the choice of ensemble generation and choice of the observation errors) has not been evaluated. We will base our discussion on a simple comparison between the innovation vector (the vector difference between observations and model state in the observation space) and the error covariance matrix, as presented by Lisaeter et al. (2003). A short description of the method employed to compare innovation and errors is presented below.

The innovation vector of member $j\left(\boldsymbol{\lambda}_{j}\right)$ is given as

$\lambda_{j}=\boldsymbol{d}-\mathbf{H} \boldsymbol{x}_{j}$.

We can define the second order momentum of the innovation $(\mathbf{Q})$ as

$\mathbf{Q}=\overline{\lambda_{j}} \lambda_{j}^{T}$,

where the overbar defines an ensemble average.

If we consider the model estimate and the observations to be given as a true value $\left(\mathbf{H} \boldsymbol{x}_{t}\right)$ plus an error, we obtain

$\mathbf{H} \boldsymbol{x}_{j}=\mathbf{H} \boldsymbol{x}_{t}+\boldsymbol{\epsilon}_{j}^{\bmod }$,

and

$\boldsymbol{d}=\mathbf{H} \boldsymbol{x}_{t}+\boldsymbol{\epsilon}^{\mathrm{obs}}$.

Assuming independence of the observation errors and the models errors, this leads to

$\mathbf{Q}=\overline{\left(\boldsymbol{\epsilon}^{\mathrm{obs}}-\boldsymbol{\epsilon}_{j}^{\mathrm{mod}}\right)\left(\boldsymbol{\epsilon}^{\mathrm{obs}}-\boldsymbol{\epsilon}_{j}^{\mathrm{mod}}\right)^{T}}=\mathbf{R}+\mathbf{H} \mathbf{P}_{\mathrm{e}} \mathbf{H}^{T}$,

where the overbar means an ensemble average. Evaluation of the quality of the error estimates can now be simply done by

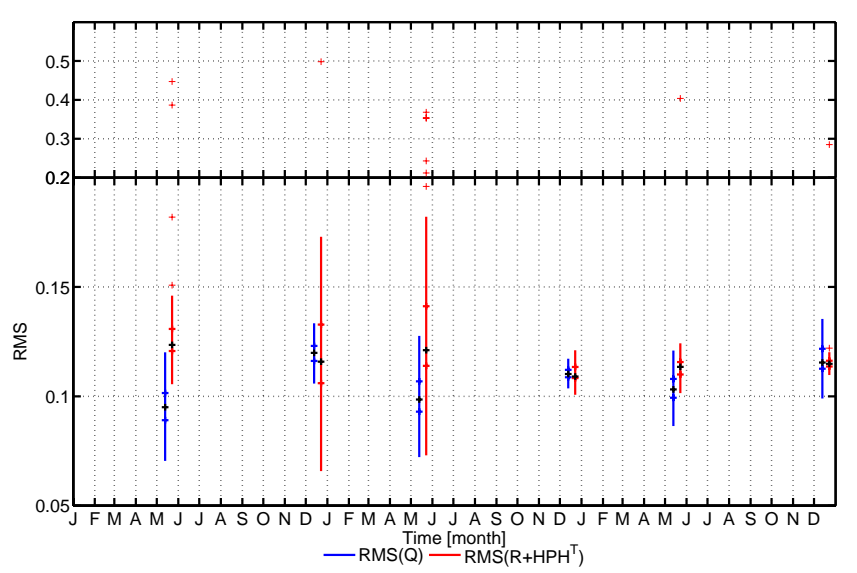

Fig. 11. Boxplot showing the RMS of the innovation covariance matrix $(\operatorname{RMS}(\mathbf{Q}))$ in blue and the RMS of the model plus observation error-covariance matrix $\left(\operatorname{RMS}\left(\mathbf{R}+\mathbf{H P}_{\mathrm{e}} \mathbf{H}^{T}\right)\right)$ in red during May and December in IC simulation. Thin crosses denote the outliers, while the end (beginning) of the whisker corresponds to the $3 \mathrm{rd}$ (1st) quartile plus (minus) 1.5 times the interquartile range. Note that the vertical axis is non linear. All RMS estimates are taken only over cells where the observations have an ice concentration larger than 0 .

comparing the $\operatorname{RMS}(\mathbf{Q})$ to $\operatorname{RMS}\left(\mathbf{R}+\mathbf{H P}_{\mathrm{e}} \mathbf{H}^{T}\right)$, where RMS is defined by

$\operatorname{RMS}(\mathbf{Q})=\sqrt{\frac{1}{p} \operatorname{trace}(\mathbf{Q})}$.

$\operatorname{RMS}(\mathbf{Q})$ and $\operatorname{RMS}\left(\mathbf{R}+\mathbf{H P}_{\mathrm{e}} \mathbf{H}^{T}\right)$ are shown in Fig. 11 for the months of May and December. The variability of the model and observation errors during May 2005 and 2006 and during December 2005 are very large. This is due to the presence of several observation days presenting very large errors in the observations (outliers in Fig. 11). After May 2006, the variabilities of the errors and of the innovation are almost identical. The median RMS of the innovation and of the EnKF errors (forecast and observations) are commensurate (around 0.11 for the summer and winter). This could mean that we have accurately estimated the errors. However, a comparison of individual contributions (not shown) concludes that the similarity between innovation and errors is mainly due to large observation errors. Consequently, the ensemble generation method would not be optimal if used with other observation products with lower observation errors. We may be required, in this case, to increase the wind perturbation but also perturb other forcing fields such as the temperature and the radiation.

\subsection{Assimilation of sea-ice concentration and freeboard}

To better constrain the ice thickness, we can also assimilate the ice freeboard in addition to the ice concentration. As shown in Sect. 5, assimilating both variables improves 

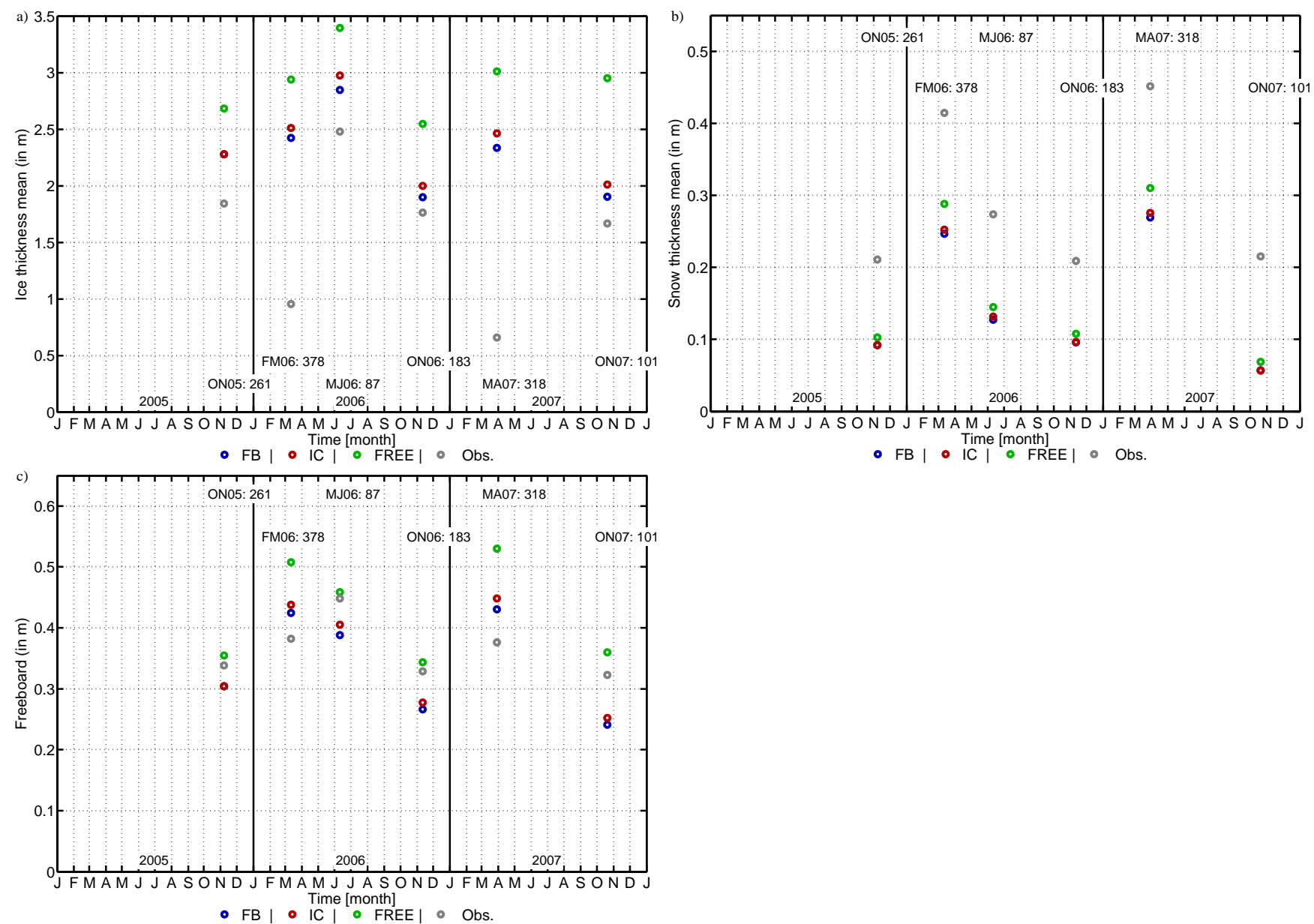

Fig. 12. Mean values of ice thickness (a), snow depth (b) and ice freeboard (c) (green for FREE, red for IC and blue for FB) in the central Arctic at the same locations as ICEsat observations; observations are in light grey. Snow depth is extracted from ice freeboard data and sea-ice thickness (derived from ICEsat freeboard Kwok and Cunningham, 2008). Snow density is assumed constant $\left(330 \mathrm{~kg} \mathrm{~m}^{-3}\right)$. The numbers at the top of the plot are the mean number of data points available each day during the corresponding ICEsat campaign.

the representation of sea-ice volume, as compared with assimilation of ice concentration alone. Ice freeboard data over 2005-2007 is cut into 6 campaigns (Table 1). Each data campaign does not contain the same number of daily data (interpolated on model grid), from 87 in MJ06 to 378 in MA06 (Fig. 12).

As ice freeboard is a combination of ice thickness and snow depth, the simulated ice freeboard could be realistic for bad reasons (error balance) and improvement on ice freeboard fields could result only from an increased realism of ice thickness or snow depth alone. The comparison of the modelled mean ice thickness over the central Arctic (Fig. 12a) shows a large overestimation in all simulations (up to $+2 \mathrm{~m}$ in FREE and $+1.5 \mathrm{~m}$ in IC and FB) during winter campaigns and a reasonable agreement during summer campaigns in IC and FB $(+25 \mathrm{~cm})$. By contrast, the snow depth is underestimated in all seasons (Fig. 12b). The simulated snow depths are quite similar in IC and FB. Without data assimilation, snow thickness is greater in FREE: $+5 \%$ in fall and summer, up to $+15 \%$ compared to IC and FB in winter. A comparison between IC and FB indicates that the assimilation of ice freeboard data improves the sea-ice thickness and slightly degrades the snow field. Unexpectedly, overestimation of ice thickness and underestimation of snow depth in FREE lead to a quite realistic ice freeboard, while IC and FB simulate an ice freeboard too small $(-5 \mathrm{~cm})$ during fall and summer (Fig. 12c). However, during winter, IC and FB ice freeboards are much more realistic than FREE ice freeboards. The main reason is the large ice thickness error, which is not balanced by the snow depth underestimation.

The mean snow depth, ice thickness and freeboard in IC and FB are qualitatively close to each other. Furthermore, these simulations show the same large scale geographical distribution of ice thickness. However, during ON07, as for the MA07 campaign (Figs. 8 and 7), ice is thinner in the centre of the Arctic Basin, by up to $70 \mathrm{~cm}$ near the North Pole 
(unobserved area due to satellite orbit) (Fig. 6bd). The intrusion of thick sea-ice in the Beaufort Sea is also less pronounced in $\mathrm{FB}$, which is more realistic.

In winter, sea-ice volume in the Arctic Ocean (as defined by Kwok et al., 2009) is closer to observations in FB than in IC (Fig. 5). In fall, the FB ice volume is smaller than observed, while multi-year sea-ice is better represented in FB (Fig. 8). This inconsistency is due to an error compensation in IC. In IC, the too thin sea-ice close to the ice edge during the minimum (new ice) is balanced by a thicker multi-year sea-ice in Beaufort gyre. As the new sea-ice close to the ice edge is almost not affected by ice freeboard data assimilation, this error balance is less important in FB.

\section{Conclusions}

The impact of sea-ice concentration and freeboard data assimilation using an ensemble Kalman filter is assessed in a global coupled ocean-sea-ice model. To do this, three types of experiments were carried out: one without data assimilation (referred to as FREE), one with ice concentration data assimilation (IC), and one with both ice concentration and freeboard data assimilation (FB). The simulations covered the entirety of the globe, over 2005-2007, with a relatively low spatial resolution $\left(2^{\circ}\right)$.

First, data assimilation experiments using synthetic observations (from a reference simulation, which is considered as the truth) were conducted in order to evaluate the data assimilation system independently of model errors. Both synthetic ice concentrations and freeboards were assimilated each day. As expected, IC sea-ice extent fits very well to synthetic data in both hemispheres. Assimilating ice freeboard data has been shown to reduce differences in total ice volume, even with the relatively short temporal coverage of the data (February to April and October to November). Ice extent is similar in IC and FB.

The second step of the study was to assimilate in the model real data of ice concentration and freeboard. For sea-ice concentration, the results are similar to those obtained in previous studies (e.g. Lisaeter et al., 2003). The errors between modelled and observed sea-ice extents are much larger in FREE than in IC in both hemispheres and in both summer and winter. Due to large sea-ice extent differences between IC and FREE, large differences of ice thickness are observed between IC and FREE after the first summer (more than $1 \mathrm{~m}$ along the Russian coast). After three years, these discrepancies do not remain confined at the sea-ice edge but propagate to the whole sea-ice pack (about $50 \mathrm{~cm}$ over all the thick sea-ice). Comparison with ice thickness reconstruction from ICESat reveals an improvement of the sea-ice thickness field in IC compared to FREE.

In order to improve the sea-ice thickness field, assimilation of sea-ice concentration data are completed by assimilating both sea-ice concentration and freeboard data. Comparison with thickness fields available during the ICESat campaign indicates an improvement of the modelled sea-ice thickness and volume in FB as compared to IC. The overestimation of sea-ice thickness in the Beaufort Gyre is decreased by $20 \mathrm{~cm}$. However, the improvement in sea-ice volume comes at the cost of less accurate snow cover; there is no effect on sea-ice extent. This improvement of sea-ice volume only concerns the Arctic region, and is minor compared to the one obtained in IC as compared to FREE.

Experiments show that if the main error of the model is in the sea-ice extent, the simulation with data assimilation reaches a new equilibrium state after the first summer both in the Arctic and in the Antarctic. One limitation of the assimilation of ice freeboard data is the presence of discontinuities in sea-ice volume during winter campaigns. An additional limit is that data used to validate the method stem from the same dataset used in the assimilation step. This study demonstrates that the methodology proposed is adequate to estimate sea-ice extent and volume. This method is thus adequate for practical application such as sea-ice reanalysis during the satellite period or in attempt of climate prediction.

Acknowledgements. H. Goosse is Senior Research Associate with the Fonds de la Recherche Scientifique (F.R.S. FNRS-Belgium). F. Massonnet is a Research Associate with the F.R.S. FNRS-Belgium. This work is partly supported by the F.R.S. FNRS, the Belgian Federal Science Policy Office, Research Program on Science for a Sustainable Development, and the Fonds Special de la Recherche of the Universite Catholique de Louvain. It is also funded by the European Commission's 7th Framework Programme, under Grant Agreement number 226520, COMBINE project. Computational ressources have been provided by the supercomputing facilities of the Universite Catholique de Louvain (CISM/UCL) and the Consortium des Equipements de Calcul Intensif en Fédération Wallonie Bruxelles (CECI) funded by the FRS-FNRS. The authors acknowledge the constructive and precise comments of the two reviewers L. Bertino and M. Bocquet.

Edited by: C. Ritz

\section{References}

Anderson, J. L.: Exploring the need for localization in ensemble data assimilation using a hierarchial ensemble filter, Physica D, 230, 99-111, 2007.

Baumgartner, A. and Reichel, E.: The World Water Balance, Mean Annual Global, Continental and Maritime Precipitation, Evaporation and Runoff, Elsevier, 1975.

Beckmann, A. and Döscher, R.: A method for improved representation of dense water spreading over topography in geopotentialcoordinate models, J. Phys. Oceanogr., 27, 581-591, 1997.

Berliand, M. and Strokina, T.: Global Distribution of the Total Amount of Clouds, Hydrometeorological, Leningrad, 71 pp., 1980 (in Russian).

Bitz, C., Fyfe, J., and Flato, G.: Sea Ice Response to Wind Forcing from AMIP Models, J. Climate, 15, 2002. 
Blanchard-Wrigglesworth, E., Bitz, C. M., and Holland, M. M.: Influence of initial conditions and climate forcing on predicting Arctic sea ice, Geophys. Res. Lett., 38, L18S03, doi:10.1029/2011GL048807, 2011.

Brodeau, L., Barnier, B., Penduff, T., Treguier, A.-M., and Gulev, S.: An ERA40 based atmospheric forcing for global ocean circulation models, Ocean Modell., 31, 88-104, 2010.

Burgers, G., van Leeuwen, P. J., and Evensen, G.: Analysis Scheme in the Ensemble Kalman Filter, Mon. Weather Rev., 126, 17191724, 1998.

Cavalieri, D., Parkinson, C., Gloersen, P., and Zwally, H.: Arctic and Antarctic sea ice concentrations from multichannel passive-microwave satellite data sets: October 1978 to December 1996, Tech. rep., User's Guide. NASA Technical Memorandum 104647, 1997.

Eastwood, S., Larsen, K. R., Lavergne, T., Nielsen, E., and Tonboe, R.: Global Sea Ice Concentration Reprocessing: Product User Manual, Tech. rep., Ocean \& Sea Ice SAF, 2010.

Ebert, E. E. and Curry, J. A.: Intermediate One-Dimensional Thermodynamic Sea Ice Model for Investigating Ice-Atmosphere Interactions, J. Geophys. Res., 98, 10085-10109, 1993.

Evensen, G.: Sequential data assimilation with a nonlinear quasigeostrophic model using Monte Carlo methods to forecast error statistics, J. Geophys. Res., 99, 10143-10162, 1994.

Evensen, G.: The Ensemble Kalman Filter: theoretical formulation and practical implementation, Ocean Dynam., 53, 343-367, 2003.

Fichefet, T. and Morales Maqueda, M.: Sensitivity of a global sea ice model to the treatment of ice thermodynamics and dynamics, J. Geophys. Res., 102, 12609-12646, 1997.

Fichefet, T., Tartinville, B., and Goosse, H.: Antarctic sea ice variability during 1958-1999: A simulation with a global ice-ocean model, J. Geophys. Res., 108, 3102, doi:10.1039/2001JC001148, 2003.

Gloersen, P., Campbell, W. J., Cavalieri, D. J., Comiso, J. C., Parkinson, C. L., and Zwally, H. J.: Arctic and Antarctic Sea Ice, 1978-1987: Satellite passive-microwave observations and analysis, NASA, Washington, DC, USA, 1992.

Goosse, H.: Modelling the large-scale behaviour of the coupled ocean-sea-ice systems., Phd Thesis, 1997.

GRDC: Observed historical discharge data from major rivers for climate model validation., Tech. rep., Global Runoff Data Centre/Max Planck Institute, first publication 1993, available at: https://www.mpimet.mpg.de/fileadmin/publikationen/ Reports/max_scirep_307.pdf, 2000.

Hibler, W.: A dynamic thermodynamic sea ice model, J. Oceanogr., 31, 815-846, 1979.

Houtekamer, P. L. and Mitchell, H. L.: A Sequential Ensemble Kalman Filter for Atmospheric Data Assimilation, Mon. Weather Rev., 129, 123-137, 2001.

Hunke, E. C.: Thickness sensitivities in the CICE sea ice model, Ocean Model., 34, 137-149, 2010.

Hunt, B. R., Kostelich, E. J., and Szunyogh, I.: Efficient data assimilation for spatiotemporal chaos: A local ensemble transform Kalman filter, Physica D, 230, 112-126, 2007.

Jacobs, S. S. and Comiso, J. C.: Sea Ice Oceanic Processes on the Ross Sea Continental Shelf, J. Geophys. Res., 94, 18195-18211, 1989.
Johnson, M., Proshutinsky, A., Aksenov, Y., Nguyen, A. T., Lindsay, R., Haas, C., Zhang, J., Diansky, N., Kwok, R., Maslowski, W., Hakkinen, S., Ashik, I., and de Cuevas, B.: Evaluation of Arctic sea ice thickness simulated by Arctic Ocean Model Intercomparison Project models, J. Geophys. Res., 117, C00D13, doi:10.1029/2011JC007257, 2012.

Kalnay, E., Kanamitsu, M., Kistler, R., Collins, W., Deaven, D., Gandin, L., Iredell, M., Saha, S., White, G., Woollen, J., Zhu, Y., Chelliah, M., Ebisuzaki, W., Higgins, W., Janowiak, J., Mo, K., Ropelewski, C., Wang, J., Leetmaa, A., Reynolds, R., Jenne, R., and Joseph, D.: The NCEP/NCAR 40-year reanalysis project, B. Am. Meteorol. Soc., 77, 437-471, 1996.

Keppenne, C. L. and Rienecker, M. M.: Initial Testing of a Massively Parallel Ensemble Kalman Filter with the Poseidon Isopycnal Ocean General Circulation Model, Mon. Weather Rev., 130, 2951-2965, 2002.

Kwok, R. and Cunningham, G.: ICESat over Arctic sea ice: Estimation of snow depth and ice thickness, J. Geophys. Res., 113, C08010, 10.1029/2008JC004753, 2008.

Kwok, R., Cunningham, H. J., and Yi, D.: Ice, Cloud, and land Elevation Satellite (ICESat) over Arctic sea ice: Retrieval of freeboard, J. Geophys. Res., 112, C12013, 10.1029/2006JC003978, 2007.

Kwok, R., Cunningham, G., Wensnahan, M., Rigor, I., Zwally, H., and Yi, D.: Thinning and volume loss of the Arctic Ocean sea ice cover: 2003-2008, J. Geophys. Res., 114, C07005, doi:10.1029/2009JC005312, 2009.

Lindsay, R. W. and Zhang, J.: Assimilation of Ice Concentration in an Ice-Ocean Model, J. Athmos. Ocean. Technol., 23, 742-749, 2006.

Lisaeter, K., Rosanova, J., and Evensen, G.: Assimilation of ice concentration in a coupled ice-ocean model, using the Ensemble Kalman filter, Ocean Dynam., 53, 368-388, doi:10.1007/s10236003-0049-4, 2003.

Lisaeter, K. A., Evensen, G., and Laxon, S.: Assimilating synthetic CryoSat sea ice thickness in a coupled ice-ocean model, J. Geophys. Res., 112, C07023, doi:10.1029/2006JC003786, 2007.

Madec, G.: NEMO, the Ocean Engine, Tech. rep., IPSL Université P. et M. Curie, B102 T15-E5, 4 place Jussieu, Paris cedex 5, 2008.

Massonnet, F., Fichefet, T., Goosse, H., Vancoppenolle, M., Mathiot, P., and König Beatty, C.: On the influence of model physics on simulations of Arctic and Antarctic sea ice, The Cryosphere, 5, 687-699, doi:10.5194/tc-5-687-2011, 2011.

Maykut, G.: The geophysics of sea ice, New York, Plenium, 1986.

Oke, P. R., Sakov, P., and Corney, S. P.: Impacts of localisation in the EnKF and EnOI: experiments with a small model, Ocean Dynam., 57, 32-45, 2007.

Rothrock, D. and Zhang, J.: Arctic Ocean sea ice volume: What explains its recent depletion?, J. Geophys. Res., 110, C01002, doi:10.1029/2004JC002282, 2005.

Rothrock, D., Percival, D., and Wensnahan, M.: The decline in arctic sea-ice thickness: Separating the spatial, annual, and interannual variability in a quarter century of submarine data, J. Geophys. Res., 113, C05003, 2008.

Sakov, P. and Bertino, L.: Relation between two common localisation methods for the EnKF, Computational Geosciences, 2010.

Semtner, A.: A model for the thermodynamic growth of sea ice in numerical investigations of climate, J. Phys. Oceanogr., 6, 379- 
389, 1976.

Stark, J. D., Ridley, J., Martin, M., and Hines, A.: Sea ice concentration and motion assimilation in a sea ice-ocean model, J. Geophys. Res., 113, C05S91, 2008.

Steele, M., Morley, R., and Ermold, W.: PHC: a global ocean hydrography with a high quality Arctic Ocean, J. Climate, 14, 2079-2087, 2001.

Timmermann, R., Worby, A., Goosse, H., and Fichefet, T.: Utilizing the ASPeCt sea ice thickness data set to evaluate a global coupled sea ice-ocean model, J. Geophys. Res., 109, C07017, 2004.

Timmermann, R., Goosse, H., Madec, G., Fichefet, T., Ethe, C., and Dulière, V.: On the representation of high latitude processes in the ORCALIM global coupled sea ice-ocean model, Ocean Model., 8, 175-201, 2005.

Trenberth, K., Olson, J., and Large, W.: A global ocean wind stress climatology based on the ECMWF analyses, Tech. rep., National Center for Atmospheric Research, Boulder, NCAR/TN338+STR, 1989.

Uotila, P., O'Farrell, Marsland, S., and Bi, B.: A sea-ice sensitivity study with a global ocean-ice model, Ocean Model., 51, 1-18 2012.
Vancoppenolle, M., Fichefet, T., Goosse, H., Bouillon, S., Madec, G., and Morales Maqueda, M.: Simulating the mass balance and salinity of Arctic and Antarctic sea ice, 1. Model description and validation, Ocean Model., 27, 33-53, 2009.

Warren, S., Rigor, I., Untersteiner, N., Radionov, V., Bryazgin, N., Aleksandrov, Y., and Colony, R.: Snow depth on Arctic sea ice, J. Climate, 12, 1814-1829, 1999.

Watanabe, E. and Hasumi, H.: Arctic sea ice response to wind stress variations, J. Geophys. Res., 110, C11007, 10.1029/2004JC002678, 2005.

Worby, A., Geiger, C., Paget, M., Woert, M. V., Ackley, S., and DeLiberty, T.: The thickness distribution of Antarctic sea ice, J. Geophys. Res., 113, C05S92, 10.1029/2007JC004254, 2008.

Xie, P. and Arkin, P.: Global precipitation : A 17-year monthly analysis based on gauge observations, satellite estimate, and numerical model outputs, B. Am. Meteorol. Soc., 78, 2539-2558, 1997.

Yi, D. and Zwally, J.: Arctic Sea Ice Freeboard and Thickness, Tech. rep., Boulder, Colorado USA: National Snow and Ice Data Center, Digital media, 2010.

Zwally, H. J., Yi, D., Kwok, R., and Zhao, Y.: ICESat measurements of sea ice freeboard and estimates of sea ice thickness in the Weddell Sea, J. Geophys. Res., 113, C02S15, doi:10.1029/2007JC004284, 2008. 